\title{
Stroke and Hypertension: Recent Trends of High Blood Pressure and the Decline in Stroke Mortality
}

\author{
Daniel T Lackland
}

\begin{abstract}
High blood pressure has long been recognized as associated with increased risk of stroke. Basically, the higher the systolic blood pressure, the greater the risk of stroke. The high blood pressure risks are evident in both genders, all ages and all population. Since the 1970 s, evidence has been generated determining that lowering the blood pressure reduces the risks of stroke. At the population level, the blood pressure distributions in the United States have shifted to the left, i.e. current population blood pressure levels are lower than previous decades. These lower blood pressures are associated with lower stroke risks. The lower blood pressures are attributed to structured programs implemented specifically to lower blood pressure in the population, clinical guidelines detailed to pharmacologically lower pressures, hypertension prevention efforts and programs, and additional resources devoted to lower blood pressure. These intervention and prevention have been effective in lowering blood pressures and stroke risk reduction. While additional improvements remain to be accomplished globally, the models of lower blood pressures and hypertension should be considered one of the major public health success stories in the past 50 years and a major objective for population risk reduction throughout the world.
\end{abstract}

Keywords: Blood pressure, Disease risks, Hypertension, Population, Stroke.

How to cite this article: Lackland DT. Stroke and Hypertension: Recent Trends of High Blood Pressure and the Decline in Stroke Mortality. Hypertens J 2015;1(1):22-27.

Source of support: Nil

Conflict of interest: None

\section{INTRODUCTION}

The diagnosis, treatment, management and prevention of high blood pressure (BP) represent one of the major global public health issues of the past century. Every country and population is affected by elevated BP with adverse outcomes, such as stroke and end-stage renal disease

Professor and Director

Department of Neurology, Division of Translational Neurology and Population Studies, Medical University of South Carolina Harborview Office Tower, Charleston, SC, USA

Corresponding Author: Daniel T Lackland, Professor and Director, Department of Neurology, Division of Translational Neurology and Population Studies, Medical University of South Carolina, Harborview Office Tower, Suite 501, Charleston, SC 29425, USA, Phone: 843-876-1141, e-mail: lackland@musc.edu with the associated economic burden. However, the successful efforts for hypertension control and prevention have manifested into a public health success story with global implications. ${ }^{1}$ The World Hypertension League is positioned to address the global issues through member societies and regional offices.

\section{HYPERTENSION RISKS}

Hypertension risks were first recognized with the association of BP levels and stroke risks in the 1920s. ${ }^{2}$ Early clinical studies identified clear benefits of lowering BP on reducing stroke deaths. ${ }^{3}$ Several studies were stopped earlier as the benefits of the treatment of high BP were evident. ${ }^{4,5}$ Similarly, other studies reported a consistent pattern of benefit of hypertension treatment. ${ }^{6,7}$ The evidence for the benefits of lower blood is strong, continuous, graded, consistent, independent, predictive, and etiologically significant for those with or without comorbid conditions including coronary heart disease. ${ }^{8,9}$ These results were so significant such to be used in development and implement the national programs, such as National High BP Education Program (NHBPEP) in the USA that promoted hypertension screenings and patient treatment. ${ }^{10}$

Lowering high BP is proposed as a major factor for the reduction in stroke death rates during the last half of the 20th century and early 21 st century. ${ }^{11}$ Specifically, hypertension-related outcomes, such as stroke mortality was reduced from $88 / 100,000$ in 1950 to $23 / 100,000$ in 2010, with consistent reductions in mortality for all age, race and sex groups in the US as well as other countries is consistent with high BP recognition and reduction campaigns initiated during the same period..$^{12}$ These BP reduction strategies included clinical interventions for hypertension and public health efforts focused on lifestyle for the shifting of BP distributions. ${ }^{1}$ The decline in hypertension-related outcomes significantly accelerated after the introduction of tolerable antihypertensive drug therapy in the 1960s. ${ }^{13}$

Epidemiological studies have shown elevated BP is the most important determinant of the risk of stroke with a linear relationship beginning at relatively low levels of systolic and diastolic BP. ${ }^{14}$ Risk factors for high BP, including increased body mass, obesity, increased waist 
circumference, higher alcohol intake, and greater sodium intake are also associated with increased risks for high BP related outcomes. ${ }^{15}$ It is estimated that the overwhelming majority of strokes each year could be prevented through awareness and optimal management of hypertension. ${ }^{16}$

\section{PREVALENCE OF HIGH BLOOD PRESSURE AND BLOOD PRESSURE DISTRIBUTION}

Recent estimates from population surveillance identify over 68 million individuals with high BP warranting some form of monitoring or treatment in the US alone. ${ }^{17-19}$ Global hypertension prevalence estimates of 1 billion individuals, with an estimated 7.1 million deaths per year attributable to hypertension. ${ }^{20}$ As the population ages, the number of individuals with elevated BP increases. ${ }^{1,21,22}$ The substantial and increasing prevalence of elevated BP combined with the evidence-based benefit of hypertension treatment have led to the prioritization of prevention and control programs among governmental, professional and voluntary agencies with considerable success achieved. ${ }^{1}$ The percentage of patients with hypertension receiving treatment has increased to where more than $90 \%$ of the population knows the relationship between high BP and stroke, nearly $70 \%$ of the adult hypertensive population are treated, and nearly half of those treated for high BP are controlled to below $140 / 90 \mathrm{~mm} \mathrm{Hg}^{23,24}$

The mean systolic BP (SBP) for the US adult population declined from $131 \mathrm{~mm} \mathrm{Hg}$ in 1960 to $122 \mathrm{~mm} \mathrm{Hg}$ in 2008. ${ }^{1,25,26}$ Between 1959 and 2010, median and 90th percentile systolic BP declined by approximately 16 mm Hg. ${ }^{1}$ This declining shift in BP distributions was consistent for different age groups, including 18 to 29 years, 18 to 39 years, 30 to 59 years, and 60 to 74 years. ${ }^{1}$ These population wide changes in reduced BP seen within the last five decades have been associated with the large accelerated reductions in stroke mortality. ${ }^{1}$ The shift to the left in mean arterial BP is more pronounced in older Americans who have a greater prevalence, who are more likely to visit physicians and who are on BP treatment, than in younger people, even though they may be less likely to achieve goal BP. Goff et al described a gradual downward shift of the entire distribution of BP levels in the general population going back to the early 1900 s. $^{27}$ The recognition of elevated BP as a risk factor appears to have affected BP levels and subsequent stroke mortality risks. While the decline in stroke mortality and lowering BP may have appeared to be evident before this recognition and treatment of hypertension, the effects of lowered BP is most evident after the population-based campaigns. ${ }^{1}$ Hypertension treatment and control rates have consistently increased since the early 1970s. ${ }^{1}$ This improvement is seen in all subsets of the population. Further demonstrating the impact of treatment, SBP is lower for treated hypertensive than untreated groups. All populations have shown significant improvements during the time period. Likewise a reduction in mean SBP has been observed for all age, race, and gender groups. ${ }^{1}$ The 90th percentile SBP levels have been lowered over the past decades suggesting significant impact of hypertension treatment and control. Similarly, the 10th percentiles have also been lower through the past years. ${ }^{1}$ The reduction in these lower BP levels is most likely the result of lifestyle and nonpharmacologic interventions and public health activities.

Pharmacological treatment of BP focuses on individuals with hypertension defined as a value of 140/90 $\mathrm{mm} \mathrm{Hg}$ or greater, the risk of stroke begins at BP below 140/90 mm Hg levels. ${ }^{28}$ A meta-analysis of 61 studies found each incremental rise of $20 \mathrm{~mm} \mathrm{Hg} \mathrm{SBP}$ and $10 \mathrm{~mm} \mathrm{Hg}$ DBP was associated with a two-fold increase in death rates from stroke. ${ }^{1}$ In addition, age-related rise in SBP is primarily responsible for an increase in both incidence and prevalence of hypertension with a lifetime risk of hypertension to be approximately $90 \%$ for men and women, who were nonhypertensive at 55 or 65 years and survived to age 80 to $85 .{ }^{29,30}$ These risks demonstrate the impact of BP on outcomes. ${ }^{31}$ The increase of $\mathrm{BP}$ to hypertensive categories with increasing age is evident by patterns and trends indicating that the 4-year rates of progression to hypertension are 50\% for those 65 years and older with BP in the 130 to $139 / 85$ to $89 \mathrm{~mm} \mathrm{Hg}$ range and 26\% for those with $\mathrm{BP}$ between 120 and 129/ 80 to $84 \mathrm{~mm} \mathrm{Hg}$ range. ${ }^{32}$

Greatest benefits of BP reduction are evident in the severe category of elevated BP levels. ${ }^{33,34}$ These extreme $\mathrm{BP}$ levels are more prevalent among the high stroke risk populations, especially African Americans, but the values have been reduced with treatment with corresponding risk reduction. ${ }^{35,36}$ However, hypertension emergencies, crises and malignant hypertension represent a small percent of the population with high BP. Up to $2 \%$ of patients with hypertension develop a hypertensive crisis at some point in their lifetime. ${ }^{37,38}$

\section{OBSERVATIONAL STUDIES}

Cohort studies have demonstrated increased attributable risks associated with elevated BP levels. ${ }^{1,39,40}$ High BP was identified as responsible for the largest number of cardiovascular and stroke deaths in the US. ${ }^{1,36}$ The INTERSTROKE study concluded the contribution of various risk factors to the burden of stroke worldwide to be $34.6 \%$ for hypertension (CI 30.4-39.1). ${ }^{41}$ In addition, it was estimated that among treated hypertensives, approximately $45 \%$ of all strokes might be attributed to uncontrolled $\mathrm{BP}^{42}$ Such risk estimates are consistent for all components of the population with significant 
population-attributable risk for elevated BP and stroke mortality. ${ }^{1}$ The relationship between BP and risk of cardiovascular disease (CVD) events is demonstrated over time, continuous, consistent, and independent of other risk factors. The linear relationship holds true for all demographics indicating the higher BP the greater the risk of stroke mortality.

\section{CLINICAL TRIALS}

The benefit of hypertension treatment to reduce stroke risks is evident with the effective number needed-totreat (NNT) estimates. Treatment of high BP has been associated with reductions in stroke incidence by 35 to $40 \%$; myocardial infarction, 20 to $25 \%$; and heart failure, more than $50 \% .{ }^{43}$ It is estimated that among patients with stage one hypertension (SBP 140-159 mm Hg and/or DBP 90-99 $\mathrm{mm} \mathrm{Hg}$ ) and additional cardiovascular risk factors, achieving a sustained $12 \mathrm{~mm} \mathrm{Hg}$ reduction in SBP over 10 years will prevent one cardiovascular event for every 11 patients treated. In the presence of CVD or target organ damage, only nine patients would require such $\mathrm{BP}$ reductions to prevent death. ${ }^{44}$ Clinical trials have demonstrated that control of systolic hypertension reduces stroke risks. ${ }^{45-48}$ Results from the hypertension detection and follow-up program (HDFP) showed that reductions of $4.7 \mathrm{~mm} \mathrm{Hg}$ reduced stroke mortality by $17.6 \%$. ${ }^{49}$

Several studies focused on secondary prevention. The Dutch TIA trial study and other major trials have shown significant lower rates of recurrent stroke with lower BP. ${ }^{50}$ The secondary prevention of small subcortical strokes (SPS3) trial showed targeting a systolic BP less than $130 \mathrm{~mm} \mathrm{Hg}$ is likely to reduce recurrent stroke by about $20 \%(p=0.08)$ and significantly reduced intracerebral hemorrhage by two-third. ${ }^{51}$ The ongoing systolic blood pressure intervention trial (SPRINT) is a 2-arm, multicenter, randomized clinical trial designed to test whether a treatment program aimed at reducing SBP to a lower goal than currently recommended will reduce cardiovascular disease and stroke risk as well as cognitive function. ${ }^{52}$

\section{HYPERTENSION TREATMENT GUIDELINES}

From the 1970s, high BP guidelines have been developed to guide clinical practice with high impact on elevated BP control and management of high BP. ${ }^{8,14,53-61}$ The treatment guidelines have included recommendations focused on the reduction of hypertension-related conditions including stroke. The guidelines have evolved as evidence about the benefits of treating to lower BP levels becomes available as well as study results, which differentiate the effectiveness of the different classes of treatment. A major contribution of the clinical guidelines remains the definition of hypertension and BP treatment goals. With each set of guidelines, the BP level for treatment and goals have typically been lowered. These recommendations may have impact population BP levels as systolic BP have been lower with the evolving guidelines. These guidelines recommendations for clinical management are also used for public health hypertension control efforts. The implementation of the guidelines to address the population at risks is designed to impact the disease risk. ${ }^{62}$

\section{STRUCTURED PROGRAMS}

The impact of elevated BP on the population has led to the establishment of prevention and management strategies for hypertension as major public health objectives with the premise that if the elevation of BP with age can be prevented or reduced, outcomes, such as stroke will be affected. ${ }^{1}$ This concept has led to the implementation of public health strategies and programs to reduce BP in the population as an effort to lower risks. The traditional global risk factors include excess body weight; excess dietary sodium intake; suboptimal physical activity; inadequate intake of fruits, vegetables, and potassium; and excess alcohol intake. ${ }^{63}$ These programs are aimed at working with the food industry and restaurants as well as establishing policies to reduce salt in the prepared and processed food, encouraging the consumption of more fresh fruits and vegetables, increasing community participation in physical activity, detecting and tracking high BP at churches, worksites and community events and public education campaigns. ${ }^{64,65}$

This population-based approach complements the clinical hypertension treatment and management. Primary prevention strategies are implemented to reduce the BP levels in the population. The desired outcome is the shift to the left of BP distributions in the general population delays in onset of hypertension and BPassociated morbidity and mortality. ${ }^{1}$ Risk estimates from the two decades ago predicted a $5 \mathrm{~mm} \mathrm{Hg}$ reduction of SBP in the adult population would result in a $14 \%$ overall reduction in mortality due to stroke. ${ }^{66}$ The reduction in SBP is consistent with the decline in stroke mortality, and corresponds to the predicted lower stroke mortality rates. ${ }^{1}$

In summary, multiple evidence sources identify the impact of BP reduction on stroke mortality decline in many population demonstrating the impact of high BP control and prevention. Epidemiological and observational studies over the past five decades consistently identify a significant association of BP level and stroke mortality for all genders, races and cultures, as well as all age groups. Clinical trials have confirmed the consistent findings of reduced BP and lower stroke mortality rates. The trends in stroke risks with $\mathrm{BP}$ 
level identified from the observational epidemiologic studies are consistent with the evidence for the levels of BP reduction from clinical trials. The evidence is strong such that clinical guidelines and intervention programs focus on BP management and lower BP levels for primary and secondary stroke prevention. These comprehensive components of population risk reduction are ideal models for the clinical medicine and population health partnership. The accelerated decline in stroke mortality beginning in the 1970s is consistent with the aggressive hypertension treatment and control strategies implemented in that time period. In addition, with an aging and heavier population, the pool of at-risk individuals has increased substantially during this time period. The decrease in BP with drug therapy as assessed in clinical settings and widespread public health interventions in the general population appears to be the major determinant for reduction in the risk of hypertension-related outcomes. These success stories provide a tremendous opportunity for partnerships and the world hypertension league specifically addressing the global burden of elevated BP.

\section{REFERENCES}

1. Lackland DT, Roccella EJ, Deutsch AF, Fornage M, George MG, Howard G, Kissela BM, Kittner SJ, Lichtman JH, Lisabeth LD, et al. Factors influencing the decline in stroke mortality. Stroke 2014;45:315-353.

2. Kuller LH. Epidemiology and prevention of stroke, now and in the future. Epidemiol Rev 2000;22:14-17.

3. O'Donnell MJ, Xavier D, Liu L, Zhang H, Chin SL, RaoMelacini P, Rangarajan S, Islam S, Pais P, McQueen MJ, et al. Risk factors for ischemic and intracerebral hemorrhagic stroke in 22 countries (the INTERSTROKE study): a casecontrol study. Lancet 2010;376:112-123.

4. Burt VL, Whelton P, Roccella EJ, Brown C, Cutler JA, Higgins M, Horan MJ, Labarthe D. Prevalence of hypertension in the US adult population. Results from the Third National Health and Nutrition Examination Survey, 1988-1991. Hypertension 1995;25:305-313.

5. Hajjar I, Kotchen TA. Trends in prevalence, awareness, treatment, and control of hypertension in the United States, 1988-2000. JAMA 2003;290:199-206.

6. Centers for disease control and prevention (CDC). Vital signs: prevalence, treatment, and control of hypertension-United States, 1999 to 2002 and 2005 to 2008. MMWR Morb Mortal Wkly Rep 2011;60:103-108.

7. World Health Organization. The World Health Report 2002: Reducing risks, promoting healthy life. Geneva, Switzerland. Available at: http://www.who.int/whr/2002/. Accessed on: July 23, 2012.

8. The sixth report of the Joint National Committee on prevention, detection, evaluation, and treatment of high blood pressure. Arch Intern Med 1997;157:2413-2446.

9. Burt VL, Cutler JA, Higgins M, Horan MJ, Labarthe D, Whelton P, Brown C, Roccella EJ. Trends in the prevalence, awareness, treatment, and control of hypertension in the adult US population. Data from the health examination surveys, 1960 to 1991. Hypertension 1995;26:60-69.

10. Roccella EJ. The National High Blood Pressure Education Program. Hypertension: A Companion to Brenner and Rector's The Kidney. 2nd edition. In: Oparil S, Weber M, editors. Philadelphia, PA: Elsevier Saunders; 2005.

11. Wright JD, Hughes JP, Ostchega Y. Mean systolic and diastolic blood pressure in adults aged 18 and over in the United States, 2001 to 2008. National health statistics reports; no 35. Hyattsville, MD: National Center for Health Statistics; 2011.

12. Yoon SS, Ostchega Y, Louis T. Recent trends in the prevalence of high blood pressure and its treatment and control, 1999 to 2008. NCHS Data Brief, no. 48. Hyattsville, MD: National Center for Health Statistics; 2010.

13. Goff DC, Howard G, Russell GB, Labarthe DR. Birth cohort evidence of population influences on blood pressure in the United States, 1887-1994. Ann Epidemiol 2001;11:271-279.

14. Chobanian AV, Bakris GL, Black HR, Cushman WC, Green LA, Izzo JL Jr, Jones DW, Materson BJ, Oparil S, Wright JT Jr, et al. The Seventh Report of the Joint National Committee on Prevention, Detection, Evaluation, and Treatment of High Blood Pressure: the JNC 7 report. JAMA 2003;289:2560-2572.

15. Franklin SS, Gustin WT, Wong ND, Larson MG, Weber MA, Kannel WB, Levy D. Hemodynamic patterns of age-related changes in blood pressure. The Framingham Heart Study. Circulation 1997;96:308-315.

16. Vasan RS, Beiser A, Seshadri S, Larson MG, Kannel WB, D'Agostino RB, Levy D. Residual lifetime risk for developing hypertension in middle-aged women and men: The Framingham Heart Study. JAMA 2002;287:1003-1010.

17. Lloyd-Jones DM, Hong Y, Labarthe D, Mozaffarian D, Appel LJ, Van Horn L, Greenlund K, Daniels S, Nichol G, Tomaselli GF, et al. Defining and setting national goals for cardiovascular health promotion and disease reduction: the American Heart Association's strategic Impact Goal through 2020 and beyond. Circulation 2010;121:586-613.

18. Vasan RS, Larson MG, Leip EP, Kannel WB, Levy D. Assessment of frequency of progression to hypertension in nonhypertensive participants in the Framingham Heart Study: a cohort study. Lancet 2001;358:1682-1686.

19. Lip GY, Beevers M, Beevers DG. Complications and survival of 315 patients with malignant-phase hypertension. J Hypertens 1995;13:915-924.

20. Phillips SJ, Whisnant JP. Hypertension and the brain. The National High Blood Pressure Education Program. Arch Intern Med 1992;152:938-945.

21. Saunders E. Hypertension in African-Americans. Circulation 1991;83:1465-1467.

22. Shea S, Misra D, Ehrlich MH, Field L, Francis CK. Predisposing factors for severe, uncontrolled hypertension in an inner-city minority population. N Engl J Med 1992;327:776-781.

23. Zampaglione B, Pascale C, Marchisio M, Cavallo-Perin P. Hypertensive urgencies and emergencies. Prevalence and clinical presentation. Hypertension 1996;27:144-147.

24. Shayne PH, Pitts SR. Severely increased blood pressure in the emergency department. Ann Emerg Med 2003;41:513-529.

25. Lackland DT, Keil JE, Gazes PC, Hames CG, Tyroler HA. Outcomes of black and white hypertensive individuals after 30 years of follow-up. Clin Exp Hypertens 1995;17:1091-1105.

26. Gazes PC, Lackland DT, Mountford WK, Gilbert GE, Harley RA. Comparison of cardiovascular risk factors for high brachial pulse pressure in blacks versus whites 
(Charleston Heart Study, Evans County Study, NHANES I and II Studies). Am J Cardiol 2008;102:1514-1517.

27. Goff DC, Howard G, Russell GB, Labarthe DR. Birth cohort evidence of population influences on blood pressure in the United States, 1887-1994. Ann Epidemiol 2001;11:271-279.

28. Li C, Engstrom G, Hedblad B, Berglund G, Janzon L. Blood pressure control and risk of stroke: a population-based prospective cohort study. Stroke 2005;36:725-730.

29. Neal B, MacMahon S, Chapman N. Effects of ACE inhibitors, calcium antagonists, and other blood-pressure-lowering drugs: results of prospectively designed overviews of randomised trials. Blood Pressure Lowering Treatment Trialists' Collaboration. Lancet 2000;356:1955-1964.

30. Ogden LG, He J, Lydick E, Whelton PK. Long-term absolute benefit of lowering blood pressure in hypertensive patients according to the JNC VI risk stratification. Hypertension 2000;35:539-543.

31. Kostis JB, Davis BR, Cutler J, Grimm RH Jr, Berge KG, Cohen JD, Lacy CR, Perry HM Jr, Blaufox MD, WassertheilSmoller S, et al. Prevention of heart failure by antihypertensive drug treatment in older persons with isolated systolic hypertension. SHEP Cooperative Research Group. JAMA 1997;278:212-216.

32. Prevention of stroke by antihypertensive drug treatment in older persons with isolated systolic hypertension. Final results of the Systolic Hypertension in the Elderly Program (SHEP). SHEP Cooperative Research Group. JAMA 1991; 265:3255-3264.

33. Staessen JA, Thijs L, Fagard R, O'Brien ET, Clement D, de Leeuw PW, Mancia G, Nachev C, Palatini P, Parati G, et al. Predicting cardiovascular risk using conventional vs ambulatory blood pressure in older patients with systolic hypertension. Systolic Hypertension in Europe Trial Investigators. JAMA 1999;282:539-546.

34. Black HR, Elliott WJ, Neaton JD, Grandits G, Grambsch P, Grimm RH Jr, Hansson L, Lacouciere Y, Muller J, Sleight P, etal. Baseline characteristics and early blood pressure control in the CONVINCE Trial. Hypertension 2001;37:12-18.

35. Cushman WC, Ford CE, Cutler JA, Margolis KL, Davis BR, Grimm RH, Black HR, Hamilton BP, Holland J, NwachukuC, et al. Success and predictors of blood pressure control in diverse North American settings: the antihypertensive and lipid-lowering treatment to prevent heart attack trial (ALLHAT). J Clin Hypertens (Greenwich) 2002;4:393-404.

36. Lackland DT, Egan BM, Mountford WK, Boan AD, Evans DA, Gilbert G, McGee DL. Thirty-year survival for black and white hypertensive individuals in the Evans County Heart Study and the Hypertension Detection and Follow-up Program. J Am Soc Hypertens 2008;2:448-454.

37. Borhani NO, Mercuri M, Borhani PA, Buckalew VM, CanossaTerris M, Carr AA, Kappagoda T, Rocco MV, Schnaper HW, Sowers JR, et al. Final outcome results of the Multicenter Isradipine Diuretic Atherosclerosis Study (MIDAS). A randomized controlled trial. JAMA 1996;276:785-791.

38. Devereux RB, Dahlof B, Kjeldsen SE, Julius S, Aurup P, Beevers G, Edelman JM, de Faire U, Fyhrquist F, Helle Berg S, et al. Effects of losartan or atenolol in hypertensive patients without clinically evident vascular disease: a substudy of the LIFE randomized trial. Ann Intern Med 2003;139:169-177.

39. Hansson L, Hedner T, Lund-Johansen P, Kjeldsen SE, Lindholm LH, Syvertsen JO, Lanke J, de Faire U, Dahlof B,
Karlberg BE, et al. Randomised trial of effects of calcium antagonists compared with diuretics and beta-blockers on cardiovascular morbidity and mortality in hypertension: the Nordic Diltiazem (NORDIL) study. Lancet 2000;356:359-365.

40. Julius S, Alderman MH, Beevers G, Dahlof B, Devereux RB, Douglas JG, Edelman JM, Harris KE, Kjeldsen SE, Nesbitt S, et al. Cardiovascular risk reduction in hypertensive black patients with left ventricular hypertrophy: the LIFE study. J Am Coll Cardiol 2004;43:1047-1055.

41. Kjeldsen SE, Lyle PA, Kizer JR, Dahlof B, Devereux RB, JuliusS, Beevers G, de Faire U, Fyhrquist F, Ibsen H, et al. The effects of losartan compared to atenolol on stroke in patients with isolated systolic hypertension and left ventricular hypertrophy. The LIFE study. J Clin Hypertens (Greenwich) 2005; 7:152-158

42. Lindholm LH, Ibsen H, Dahlof B, Devereux RB, Beevers G, de Faire U, Fyhrquist F, Julius S, Kjeldsen SE, Kristiansson K, etal. Cardiovascular morbidity and mortality in patients with diabetes in the Losartan Intervention For endpoint reduction in hypertension study (LIFE): a randomised trial against atenolol. Lancet 2002;359:1004-1010.

43. Mancia G, Brown M, Castaigne A, de Leeuw P, PalmerCR, Rosenthal T, Wagener G, Ruilope LM. Outcomes with nifedipine GITS or Co-amilozide in hypertensive diabetics and nondiabetics in intervention as a goal in hypertension (INSIGHT). Hypertension 2003;41:431-436.

44. Mochizuki S, Dahlof B, Shimizu M, Ikewaki K, Yoshikawa M, Taniguchi I, Ohta M, Yamada T, Ogawa K, Kanae K, et al. Valsartan in a Japanese population with hypertension and other cardiovascular disease (Jikei Heart Study): a randomised, open-label, blinded endpoint morbidity and mortality study. Lancet 2007;369:1431-1439.

45. Reims HM, Oparil S, Kjeldsen SE, Devereux RB, Julius S, Brady WE, Fyhrquist F, Ibsen H, Lindholm LH, Omvik P, et al. Losartan benefits over atenolol in non-smoking hypertensive patients with left ventricular hypertrophy: the LIFE study. Blood Press 2004;13:376-384.

46. Schrader J, Luders S, Kulschewski A, Hammersen F, PlateK, Berger J, Zidek W, Dominiak P, Diener HC. Morbidity and mortality after stroke, eprosartan compared with nitrendipine for secondary prevention: principal results of a prospective randomized controlled study (MOSES). Stroke 2005;36:1218-1226.

47. Trenkwalder P, Elmfeldt D, Hofman A, Lithell H, Olofsson B, Papademetriou V, Skoog I, Zanchetti A. The Study on cognition and Prognosis in the Elderly (SCOPE) - major $\mathrm{CV}$ events and stroke in subgroups of patients. Blood Press 2005;14:31-37.

48. Weber MA, Bakris GL, Jamerson K, Weir M, Kjeldsen SE, Devereux RB, Velazquez EJ, Dahlof B, Kelly RY, Hua TA, et al. Cardiovascular events during differing hypertension therapies in patients with diabetes. J Am Coll Cardiol 2010;56:77-85.

49. Bakris GL, Gaxiola E, Messerli FH, Mancia G, Erdine S, Cooper-DeHoff R, Pepine CJ. Clinical outcomes in the diabetes cohort of the International verapamil SR-Trandolapril study. Hypertension 2004;44:637-642.

50. A comparison of two doses of aspirin (30 mg vs $283 \mathrm{mg}$ a day) in patients after a transient ischemic attack or minor ischemic stroke. The Dutch TIA Trial Study Group. N Engl J Med 1991;325:1261-1266. 
51. The SPS3 Study Group. Blood-pressure targets in patients with recent lacunar stroke: the SPS3 randomised trial. Lancet 2013;382:507-515.

52. ClinicalTrials.gov. Systolic Blood Pressure Intervention Trial (SPRINT). Available at:http://www.clinicaltrials.gov/ct2/show/ NCT01206062?term=SPRINT\&rank=3. Accessed April 8, 2013.

53. Report of the Joint National Committee on Detection, Evaluation, and Treatment of High Blood Pressure. A cooperative study. JAMA 1977;237:255-261.

54. The 1980 report of the Joint National Committee on Detection, Evaluation, and Treatment of High Blood Pressure. Arch Intern Med 1980;140:1280-1285.

55. The 1988 report of the Joint National Committee on Detection, Evaluation, and Treatment of High Blood Pressure. Arch Intern Med 1988;148:1023-1038.

56. The 1984 Report of the Joint National Committee on Detection, Evaluation and treatment of high blood pressure. Arch Intern Med 1984;144:1045-1057.

57. The fifth report of the Joint National Committee on Detection, Evaluation, and Treatment of High Blood Pressure (JNC V). Arch Intern Med 1993;153:154-183.

58. Handler J, Lackland DT. Translation of hypertension treatment guidelines into practice: a review of implementation. J Am Soc Hypertens 2011;5:197-207.

59. James PA, Oparil S, Carter BL, Cushman WC, DennisonHimmelfarb C, Handler J, Lackland DT, LeFevre ML, MacKenzie TD, Ogedegbe O, et al. Evidence-based guideline for the management of high blood pressure in adults: report from the panel members appointed to the Eighth Joint National Committee (JNC 8). JAMA 2014;311:507-520.

60. Weber MA, Schiffrin EL, White WB, Mann S, Lindholm LH, Kenerson JG, Flack JM, Carter BL, Materson BJ, Ram CV, et al. Clinical practice guidelines for the management of hypertension in the community: a statement by the American Society of Hypertension and the International Society of Hypertension. J Clin Hypertens (Greenwich) 2014; 16:14-26.

61. Mancia G, Fagard R, Narkiewicz K, Redon J, Zanchetti A, Böhm M, Christiaens T, Cifkova R, De Backer G, Dominiczak A, et al. ESH/ESC guidelines for the management of arterial hypertension. Eur Heart J 2013;34:2159-2219.

62. Bertoia ML, Waring ME, Gupta PS, Roberts MB, Eaton CB. Implications of new hypertension guidelines in the United States. Hypertension 2012;60:639-644.

63. Whelton PK, He J, Appel LJ, Cutler JA, Havas S, Kotchen TA, Roccella EJ, Stout R, Vallbona C, Winston MC, et al. Primary prevention of hypertension: clinical and public health advisory from The National High Blood Pressure Education Program. JAMA 2002;288:1882-1888.

64. He FJ, MacGregor GA. How far should salt intake be reduced? Hypertension 2003;42:1093-1099.

65. Dannenberg AL, Drizd T, Horan MJ, Haynes SG, LeavertonPE. Progress in the battle against hypertension. Changes in blood pressure levels in the United States from 1960 to 1980. Hypertension 1987;10:226-233.

66. Stamler R. Implications of the INTERSALT study. Hypertension 1991;17(Suppl 1):I16-I20. 